\title{
A Pathway for Development of Air Traffic Control through Civil-military Integration
}

\author{
Wang xinyu Cui haolin \\ Air Force Engineering University Air Traffic Control and Navigation College
}

Keywords: Civil-military Integration, Air Traffic Control, Development

\begin{abstract}
Civil-integration isn't only inevitable for globalization of military industries, but also necessary for sustainable development. As an important component of national traffic system, air traffic control provides important guarantee for national territorial airspace security and sound development of aviation. Based on general situation of air traffic control, this paper introduces necessity for China's civil-military integration, analyzes development tendency of China's air traffic control in terms of civil-military integration and proposes several suggestions for promoting civil-military integration for air traffic control in China, being of great significance for facilitating comprehensive, coordinated and sustainable development of air traffic control.
\end{abstract}

\section{Introduction}

Civil-military integration should be upgraded into a national strategy, civil-military integration strategy should be profoundly implemented and great efforts should be made to create a new situation of building strong armies. Over the past few years, civil-military integration strategy has gained tremendous support and received extensive attention from leaders, pertinent experts and scholars. Meanwhile, great progress has been achieved in civil-military integration industry in China. As an essential part of Chinese aviation system, air traffic control plays an important role in aviation construction. In recent years, characteristics of civil-military integration has been reflected from air traffic control of China from the perspective of air traffic control operation, airspace management, collaborative decision making and information sharing, etc, which has clarified objectives of developing air traffic control in China. It is not only a development trend of Chinese aviation to establish an air traffic control mechanism based on civil-military integration, but also an inevitable choice for promoting modernization of air traffic control.

\section{General Situation of Aviation Control}

Air traffic control means that services are provided to prevent aircraft collision, aircraft collision with obstacles within maneuvering areas of airports and acceleration while maintaining air traffic in order. On a global basis, the air traffic control system may be divided into three categories as follows: Firstly, integrated system, represented by America, Japan, Canada and Brazil. Secondly, united system, represented by UK, Russia, Australia and Germany. Thirdly, coordinated system, represented by France and South Africa. A common characteristic of these three types of control systems consists in that government departments are responsible for air traffic control of civil aviation. 


\section{Necessity of Civil-military Integration for Air Traffic Control in China}

\section{Connotations of Civil-military Integration}

Civil-military integration doesn't mean simple integration of civil and military resources, whereas analysis shall be performed from the perspective of strategies and technologies.

1) Strategically, civil-military integration is a new strategic thought, which means that from the standpoints of national security and overall development strategies, military and national defense construction shall be incorporated into systems of social and economic development based on Chinese national condition according to inherent laws of relationships between national defense construction and economic construction and requirements of scientific outlook on development, to integrate national defense construction with economic construction and interact with each other for the purpose of exploring a pathway for comprehensive, coordinated and sustainable development.

2) Technologically, as a new method of resource allocation, civil-military integration, on one hand, may take advantages of both civil and military resources by optimizing resource allocation; on the other hand, it may favorably and rapidly promote military and national defense construction to simultaneously improve productivity and combat effectiveness by regulating methods of resource allocation.

\section{Necessity of Civil-military Integration}

1) Increasing Efficiency of Air Traffic Control Operations

Concerning current air traffic control operations of China, air traffic control, mainly including control handover, distance regulation, control command and coordinated announcement, is mainly exercised over aircrafts flying in different territorial airspace through military and civil aviation systems. However, many problems such as untimely unsmooth control handover, uncoordinated announcement, ineffective operations, inflexible and unscientific use of territorial airspace have happened to aforementioned operating mode and become increasingly evident with the rapid development of Chinese aviation. Thus, it is urgent to find suitable ways to make improvements. For this purpose, an integrated civil-military air traffic control system shall be implemented to make up deficiencies of present air traffic control system on the premise of maintaining basic framework of Chinese air traffic control system.

2) Strengthening Overall Guarantee of Air Traffic Control

As regards separate air traffic control of civil and military aviation, there are severe problems with equipment, regulations and talent cultivation and so on. First of all, standards for facility construction aren't unified, as a result of which technologies are incompatible and it is rather hard to share or process information. Next, owing to lack of complete laws and regulations, norms and standards for air traffic control of civil and military aviation are inconsistent. At last, training methods, standard and teaching materials for aviation talents remain to be unified. As a consequence, there is a great lack of interdisciplinary talents of civil and military aviation. To realize the strategic objective of integrating civil and military integration, it is necessary to strengthen the integration to solve problems with equipment, regulations and talent cultivation.

3) Promoting Reform of Air Traffic Control

With fast development of aviation, there has is a growing increase in total transport of public aviation. Events of military aviation have been constantly expanded from the perspective of patterns and scope. Besides, there is an increasing demand for territorial airspace. Thus, new requirements have been put forward for fast, convenient and efficient services of military and civil aviation. Only if air traffic control of civil and military aviation is integrated will it be possible to establish a scientific management system and accommodate needs for rapid development of aviation. 


\section{Development Tendency of Chinese Air Traffic Control in Civil-military Integration}

\section{Establishing a Complete Legal System for Combined Air Traffic Control Operations of Civil and Military Aviation}

Regarding command, facility construction and territorial airspace management for air traffic control operations of military and civil aviation, efforts shall be made to develop complete regulations and technical standards about air traffic control, to integrate national regulations about air traffic control.

\section{Organic Integration of Civil and Military Aviation Equipment}

It may not only reduce waste of resources, but is also important for building a rapid and stable information network platform for civil and military aviation to share information by strengthening integration of air traffic control facilities for civil and military aviation, making overlapping investment and increasing efficiency of investment in air traffic control facilities.

\section{Unified Training of Talents for Air Traffic Control}

For educational trainings about civil and military aviation, principle of "a territorial airspace, a commander" shall be complied with. Training goals and quality requirements for integrated control personnel shall be clarified, in order to unify training materials, standard and job qualification. It is also necessary to promote collaboration and exchange between civil and military aviation, to develop interdisciplinary talents suitable for development of civil and military aviation.

\section{Suggestions for Establishing a Combined Operating Mechanism for Civil-Military Air Traffic Control}

\section{Being Based on Conditions of China and Drawing Lessons from Foreign Countries}

There is still a huge gap between China and world developed countries in technical standards and experience of air traffic control. Hence, it is necessary for China to study and learn from foreign technical standards and specifications for air traffic control, whereas such specifications and standards shall be adaptable to conditions of all countries. Therefore, foreign concepts, operating mechanisms, technical specifications and standards of air traffic control must be learnt based on conditions of China. Mechanical copying shall be prohibited, while an air traffic control system suitable for conditions of China shall be sought through exploration.

\section{Coordinating Needs for Military Aviation with Development of Civil Aviation}

Development of civil aviation is critical for strengthening comprehensive national power, promoting social progress and facilitating economic growth. It plays an important role in enhancing military construction, strengthening national defense, promoting national security \& unity and facilitating economic growth. Therefore, different construction and development strategies shall be developed in civil-military integration according to their distinct needs, in order to achieve coordinated development by considering armies and people.

\section{Increasing Benefits and Ensuring Safety}

It is always an eternal theme of air traffic control to ensure safety of air traffic, which matters about stable reform or development of a country and fundamental benefits of people. Hence, civil-military integration shall aim to increase benefits in developing air traffic control to the greatest extent on the premise of guaranteeing safety. 


\section{References}

[1] Gu W, Lv Z, Hao M. Change detection method for remote sensing images based on an improved Markov random field[J]. Multimedia Tools and Applications, 2015: 1-16.

[2] Chen Z, Huang W, Lv Z. Towards a face recognition method based on uncorrelated discriminant sparse preserving projection[J]. Multimedia Tools and Applications, 2015: 1-15.

[3] Jiang D, Ying $\mathrm{X}$, Han $\mathrm{Y}$, et al. Collaborative multi-hop routing in cognitive wireless networks[J]. Wireless Personal Communications, 2015: 1-23.

[4] Lv Z, Halawani A, Feng S, et al. Multimodal hand and foot gesture interaction for handheld devices $[\mathrm{J}]$. ACM Transactions on Multimedia Computing, Communications, and Applications (TOMM), 2014, 11(1s): 10. 